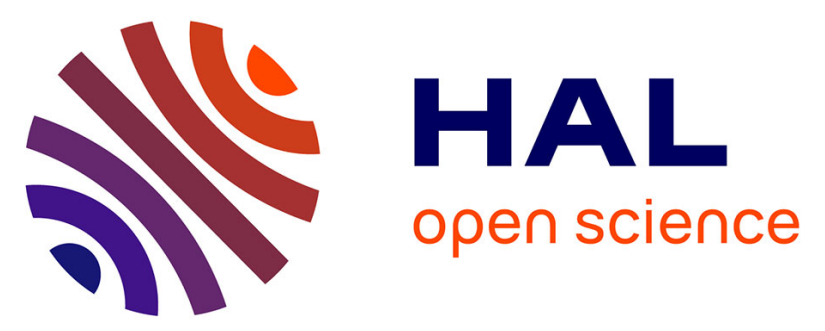

\title{
Proliferation and differentiation potential of CD133+ and CD34+ populations from the bone marrow and mobilized peripheral blood
}

Irena Koutna, Martina Peterkova, Pavel Simara, Stanislav Stejskal, Lenka

Tesarova, Michal Kozubek

\section{To cite this version:}

Irena Koutna, Martina Peterkova, Pavel Simara, Stanislav Stejskal, Lenka Tesarova, et al.. Proliferation and differentiation potential of CD133+ and CD34+ populations from the bone marrow and mobilized peripheral blood. Annals of Hematology, 2010, 90 (2), pp.127-137. 10.1007/s00277-0101058-2 . hal-00573459

\section{HAL Id: hal-00573459 \\ https://hal.science/hal-00573459}

Submitted on 4 Mar 2011

HAL is a multi-disciplinary open access archive for the deposit and dissemination of scientific research documents, whether they are published or not. The documents may come from teaching and research institutions in France or abroad, or from public or private research centers.
L'archive ouverte pluridisciplinaire HAL, est destinée au dépôt et à la diffusion de documents scientifiques de niveau recherche, publiés ou non, émanant des établissements d'enseignement et de recherche français ou étrangers, des laboratoires publics ou privés. 
Proliferation and differentiation potential of CD133+ and CD34+ populations from the bone marrow and mobilized peripheral blood.

Irena Koutna Ph.D., Martina Peterkova MSc., Pavel Simara MSc., Stanislav Stejskal MSc., Lenka Tesarova MSc., Michal Kozubek Assc. Prof., Ph.D.

Centre for Biomedical Image Analysis, Faculty of Informatics, Masaryk University, Botanicka 68a, 60200 Brno, Czech Republic

Corresponding author:

Dr. Irena Koutna Ph.D.,

qkoutna@fi.muni.cz,

Centre for Biomedical Image Analysis, Faculty of Informatics, Masaryk University

Botanicka 68a

60200 Brno

Czech Republic

Tel: +420549493969;

Fax: +420549498360 


\section{Abstract}

Objective: CD34 is the most frequently used marker for the selection of cells for bone marrow (BM) transplantation. The use of CD133 as an alternative marker is an open research topic. The goal of this study was to evaluate the proliferation and differentiation potential for hematopoiesis (short and long term) of CD133+ and CD34+ populations from bone marrow and mobilized peripheral blood.

Patients and Methods: Eight cell populations were compared: CD34+ and CD133+ cells from both the BM (CML Ph-, CML Ph+ and healthy volunteers) and mobilized peripheral blood cells. Multicolor flow cytometry and cultivation experiments were used to measure expression and differentiation of the individual populations.

Results: It was observed that the CD133+ BM population showed higher cell expansion. Another finding is that during a six-day cultivation with CFSE, more cells remained in division D0 (non-dividing cells). There was a higher percentage of CD38- cells observed on the CD133+ BM population. It was also observed that the studied populations contained very similar but not the same pools of progenitors: erythroid, lymphoid, and myeloid. This was confirmed by CFU-GM and CFU-E experiments.

The VEGFR antigen was used to monitor subpopulations of endothelial sinusoidal progenitors. The CD133+ BM population contained significantly more VEGFR+ cells.

Conclusion: Our findings suggest that the CD133+ population from the BM shows better proliferation activity and a higher distribution of primitive progenitors than any other studied population.

Keywords: CD34, CD133, HSCs transplantation, VEGFR 


\section{Introduction}

In recent years, the CD34+ antigen has been the most frequently used marker for the identification of hematopoietic stem cells (HSCs). The main source of those cells for bone marrow (BM) transplantations is peripheral blood stem cells (PBSCs) obtained using socalled mobilization of hematopoietic stem cells from healthy donors (in cases of allogeneic transplantation) or patients in remission (in cases of autologous transplantation). BM transplantation is becoming an increasingly less significant method [1]. CD34+ cells represent a heterogeneous population consisting mainly of lineage-committed progenitors and only a small hematopoietic cell population [2]. The percentage of cells capable of rapid reconstitution of sinusoidal endothelial cells (which is mandatory for the regeneration of socalled vascular niches) is thus low [3].

Recently, the importance of hematopoietic stem cell populations defined by other molecules (e.g., adhesive or chemokine receptors) has increased. Such populations can play an important role during stem cell homing to the BM and during permanent hematopoiesis reconstitution. One previously identified but frequently discussed hematopoietic stem cell marker is the molecule CD133 [4]. CD133 is reported to be a structural homolog of murine promin-1. It is a marker for stem cells with pluripotent plasticity, and CD133+ cells have been shown to be capable of induced differentiation to endothelial cells, neural cells, hepatocytes, myocytes, and osteoblasts [5].

Providing patients with a pool of cells that is capable of invoking both short-term and longterm hematopoiesis reconstitution is the most important phase of both autologous and allogeneic BM transplantation.

This study is focused on comparing eight populations of hematopoietic progenitors obtained using magnetic separation: CD133+ and CD34+ cells from both BM (CML Ph+, CML Phand healthy volunteers) and PBSCs. Flow cytometry was used for that purpose. 
The first part of the study examined the proliferation potential of all studied populations. Cell expansion was monitored together with the differentiation potential of individual populations. The main reasons for performing these experiments were 1) to provide an overview of the populations' ability to grow, expand, and proliferate and 2) to determine the share of nondividing -quiescent cells in these populations. Quiescent stem cells are defined as stem cells not currently undergoing repeated cell cycles, but that might be stimulated in the future. The presence of such a cell type is very important for long-term hematopoiesis reconstitution. The distribution of the CD38- population was measured during the isolation of individual populations as well as during short-term cultivation [6].

Another topic studied in this article is the distribution of both markers (CD133 and CD34) in individual populations. We sought to determine the degree of overlap between these populations. Recent studies [7] aimed at regeneration of sinusoidal BM cells have shown that endothelial progenitor cells (EPCs) are very important for graft engraftment. The determination of the EPC perceptual distribution was thus also included in this study. This determination was achieved by monitoring the distribution of cells expressing a VEGFR2 marker. The expression of this particular marker in the hematopoietic progenitor population defines the subpopulation of EPCs $[8,9]$.

In order to study the percentage of progenitor cells, the following lineage commitment markers were analyzed: CD71 for the erythroid lineage, CD33 for the myeloid lineage, and CD10 for the lymphoid lineage. The presence of those progenitors in grafts is very important from the perspective of short-term hematopoiesis reconstitution. The ability of individual populations to reconstitute hematopoiesis was also proven using CFU-GM and CFU-E experiments. 
Materials and Methods

\section{Patients and samples}

BM samples were taken from 12 patients diagnosed with chronic myeloid leukemia (CML) and 7 healthy volunteers. The CML samples included seven patients with de novo CML and five patients in complete molecular remission (i.e., with no leukemia cells detected by PCR and FISH). Molecular emission was evaluated according to the recommendations of European Leukemia Net. Regular evaluation of BM-treated CML patients at exact intervals was used to monitor the treatment success rate. Cytogenetic monitoring was performed at months $3,6,12$ and 18. Molecular monitoring was performed every 3 months. Patients were analyzed on month 3 (hematologic response $[\mathrm{HR}]$ ), month 6 (HR or cytogenetic response $[\mathrm{CgR}]$ ), month $12(\mathrm{CgR}$ [Philadelphia chromosome-positive $(\mathrm{Ph}+)<35 \%])$ and month 18 (complete $\mathrm{CgR}$, major molecular response [MMolR]) [10].

CML de novo diagnosed patients played a very important role in the study: large amounts of both CD34+ and CD133+ cells were obtained from their BM samples (see results). Thus, most of the experiments mentioned in the results section were done simultaneously using one sample and even multiple repetitions.

Twelve samples of mobilized PBSCs were taken from volunteers. All samples were taken after obtaining written, informed consent. All samples were processed immediately after collection.

\section{Isolation of CD34+ and CD133+ cells}

Mononuclear cells (MNCs) were isolated from the BM and PBSCs using Histopaque-1077 density gradient centrifugation (Sigma-Aldrich, St. Louis, USA). After washing three times 
with phosphate-buffered saline (PBS), the MNCs were incubated with an erythrocyte lysis buffer (ammonium chloride lysis buffer) to remove residual erythrocytes.

MNCs from the BM and PBSCs were divided into two equal parts: the first one was separated into CD34+ cells, and the second one was separated into CD133+ cells. For CD34+ and CD133+ selection, the MNCs were subjected to immunomagnetic separation using magneticactivated cell sorting (MACS) with a CD34 or CD133 MicroBead Kit (Miltenyi Biotec, Bergisch Gladbach, Germany). Positive selection of CD34 and CD133 was performed according to the instructions of the manufacturer (Miltenyi Biotec, Bergisch Gladbach, Germany). The cells were labeled with anti-CD34 or anti-CD133 antibodies, directly coupled to magnetic microbeads, and incubated for $30 \mathrm{~min}$ at $4^{\circ} \mathrm{C}$. The cells were washed with PBS and then counted in a Bürker counting chamber using a Countess Automated Cell Counter (Invitrogen, Carlsbad, USA).

We obtained eight different cell populations: three of BM CD34+ (source: CML Ph-, CML $\mathrm{Ph}+$ and healthy volunteers) three of BM CD133+ (source: CML Ph-, CML Ph+ and healthy volunteers), one of PBSC CD34+ and one of PBSC CD133+ cells. These cell populations were compared with each other.

\section{Lymphocyte depletion}

The mononuclear portion of leukocytes of the BM of healthy donors or naive de novo CML patients consists of immature myeloid cells, lymphocytes and monocytes in various percentages [11]. To enrich the primitive hematopoietic cells in the mononuclear cell fraction for FACS analysis, we depleted the lymphocytes by magnetic labeling. CD2 Microbeads $\left(\mathrm{MACS}^{\odot}\right.$ Cell Miltenyi Biotec, Bergisch Gladbach, Germany) were used to deplete the T cells and NK cells. CD19 Microbeads (MACS $^{\odot}$ Cell Miltenyi Biotec, Bergisch Gladbach, Germany) to deplete the B cells. 


\section{Cell viability}

Cell viability was evaluated through the trypan blue exclusion test using the Countess Automated Cell Counter. A single sample measurement using this counter provided the following data: live and dead cell concentration/ml, total cell concentration/ml, viability, mean diameter, and cell images.

For identification of apoptotic and necrotic cells, we also used an annexin V-FITC Kit (Miltenyi Biotec, Bergisch Gladbach, Germany) and propidium iodide (PI) (Sigma-Aldrich, St. Louis, USA) according to the manufacturer's directions. The viability of CD34+ and CD133+ cells just after isolation was $99 \pm 0.5 \%$.

\section{CFSE staining}

CD34+ and CD133+ cells were stained with $1 \mu \mathrm{M}$ 5(6)-carboxyfluorescein diacetate Nsuccinimidyl ester (CFSE; Sigma-Aldrich, St. Louis, MO, USA) as described previously [12]. These cells were cultured for six days in StemSpan Serum-Free Expansion Medium (SFEM; StemCell Technologies, Köln, Germany) with a cytokine mixture. After three and six days, the cells were harvested, washed once in PBS, and stained with anti-CD34-PE or anti-CD133PE antibodies for flow cytometric analysis. We also cultured the cells in the presence of 100 ng/ml demecolcine (Sigma-Aldrich, St. Louis, MO, USA), which arrests the cell cycle. The cultures containing demecolcine were used to establish a non-dividing cell population (CFSE maximum) during the six-day interval.

Multicolor flow cytometric analysis 
The percentage of human CD133, CD34, CD38, VEGF R2, CD10, and CD33 cells was determined using antibodies labeled with fluorescein isothiocyanate (FITC), phycoerythrin (PE), or allophycocyanin (APC). The anti-CD133 antibody conjugated to PE (clone: AC133/2) and the anti-CD38 antibody conjugated to APC were obtained from Miltenyi Biotec (Bergisch Gladbach, Germany). The anti-CD34 antibody conjugated to PE or FITC was from Becton-Dickinson (Heidelberg, Germany). The anti-human VEGR R2/KDR conjugated to FITC was from RD Systems (Minneapolis, MN, USA). The anti-CD10 antibody conjugated to PE and the anti-CD33 antibody conjugated to FITC were obtained from Immunotech (Prague, Czech Republic). The immunofluorescent staining was performed according to the manufacturer's instructions. The cells were incubated with appropriate antibodies for $30 \mathrm{~min}$ at $4{ }^{\circ} \mathrm{C}$ in the dark. Subsequently, the cells were washed once with PBS. Flow cytometric analysis was performed on the BD FACS Canto II flow cytometer (BectonDickinson, Heidelberg, Germany) using BD FACSDiva software (Becton-Dickinson, Heidelberg, Germany). A minimum of 15,000 events were analyzed in each sample. In the tables, the medians and range were used to describe data collected in flow cytometry. For flow cytometric analysis, the cells were taken from cell culture on days 0,3 , and 6 .

\section{In vitro cultivation}

Liquid culture: CD34+ or CD133+ cells were maintained in SFEM supplemented with the StemSpan CC100 cytokine mixture. The concentration of cytokines in the CC100 cocktail used for cultivating enriched HSCs was $100 \mathrm{ng} / \mathrm{mL}$ for SCF and FLT-3 ligand (Flt-3-L), and $20 \mathrm{ng} / \mathrm{mL}$ for IL-3 and IL-6.

(StemCell Technologies, Köln, Germany) at $37^{\circ} \mathrm{C}$ in $5 \% \mathrm{CO}_{2}$ and $100 \%$ humidity. The cells were cultivated for 6 days in 4-well multidishes from Nunclon (Thermo Fisher Scientific, 
Langenselbold, Germany), with $2.0 \times 10^{4}-10^{5}$ cells $/ \mathrm{ml}$ added to each well. The medium was changed after three days.

Semi-solid culture: CD133 and CD34 cells were resuspended in SFEM at $5 \times 10^{3}$ cells $/ \mathrm{ml}$ and mixed with 4 volumes of methylcellulose-based semi-solid culture medium (Human MethoCult; StemCell Technologies, Köln, Germany) containing stem cell growth factor (SCGF; $20 \mathrm{ng} / \mathrm{ml}$ ) and granulocyte colony-stimulating factor (G-CSF; $6000 \mathrm{U} / \mathrm{ml}$ ) for generating CFU-GM and SCGF (20 ng/ml) and erythropoietin (EPO; $1.5 \mathrm{U} / \mathrm{ml}$ SigmaAldrich, St. Louis, USA) for generating CFU-E. Aliquots of the mixtures $\left(10^{3}\right.$ cells $\left./ 1 \mathrm{ml}\right)$ were plated in dishes and incubated for 15 days at $37^{\circ} \mathrm{C}$ in a humidified atmosphere with $5 \%$ $\mathrm{CO} 2$ at $37^{\circ} \mathrm{C}$.

\section{Statistical analysis}

Data are presented as medians. To determine statistical significance, the nonparametric MannWhitney $U$ test was applied. The criterion for statistical significance was defined as $\mathrm{p}<0.05$. The software available at http://faculty.vassar.edu/lowry/utest.html was used for the computation of statistical values.

Results

\section{In vitro expansion}

Cell growth, absolute cell counts in the culture and population viability was monitored in parallel. At the beginning of cultivation, a given amount of cells was added to the culture. Cell growth measurements for individual populations are shown in Table 1. The median values for each group were based on $7 \mathrm{CML} \mathrm{Ph}+, 5 \mathrm{CML} \mathrm{Ph}$ - and 7 healthy volunteer samples for the $\mathrm{BM}$ and 12 samples for PBSC groups. There were no significant differences in proliferation 
activity among all of the studied sources (CML Ph+, CML Ph- and healthy volunteers) of the CD133 cells. The same was observed for the CD34 cells.

Although the concentrations of cells (cell/ml) added to the cultures differed at the beginning of each experiment, this difference did not have a statistically significant effect on the proliferation and viability of the resulting culture. A significant increase in proliferation activity was observed in cultures of CD133+ cells from the BM ( $p=0.006)$. The increase was more than two times higher (as seen in Table 1) than that observed in all CD34+ cultures. Interestingly, the differences among populations of the same cell type were insignificant.

\section{CFSE experiments}

Using the CFSE method, we were able to monitor changes in the number of divisions in individual cultures. As clearly shown in Table 2 and Figure 1, it was easy to determine the number of cell divisions and the number of cells remaining in the non-dividing state (i.e., division 0$)$.

From the perspective of cell counting, it was obvious that there was a high percentage of CD133+ cells from the BM that were not dividing, even after 6 days of culture. Despite this fact, those cells highly expressed the CD133 marker. Such cells were also found in the CD34+ BM and the CD34+ PBSC populations but at much lower concentrations (as seen in Table 2). It can thus be assumed that the distribution of non-dividing cells (which are assumed to be primitive progenitors) in the $\mathrm{CD} 133+\mathrm{BM}$ population is significantly higher than in other populations.

To confirm this assumption, we performed an independent experiment to monitor the CD133+/38- and CD34+/38- populations in parallel. Particular divisions were monitored on 
culture day 5 . We found $70 \%$ of cells were viable in the CD133+ BM population and $68 \%$ were viable in the $\mathrm{CD} 34+\mathrm{BM}$ population.

The most of cells in the D0 phase were CD133+/38- cells, while the populations of CD133+ and CD38- were minor. In subsequent generations, there were less CD133+ cells. The distributions of the individual cell types in the D0-D3 divisions on culture day 5 are clearly visible in Figure 2.

\section{CD38+ antigen determination}

The CD38- population was monitored in order to determine the distribution of primitive HSCs in individual populations. Numbers of the CD133+/38- and CD34+/38- cells from the BM and PBSCs were monitored using flow cytometry on days 0,3 and 6 during cultivation. The results are shown in Table 3. The differences between the BM populations are also documented in Figure 3. During CD38+ antigen determination in both types of CML samples $(\mathrm{Ph}+$ and $\mathrm{Ph}-)$, it was observed that the $\mathrm{CD} 133+$ population generally contained more CD38cells than the CD34+ population. The measurements on samples from healthy volunteers confirmed the same trend: the CD133+ population contained 9.2\% CD38- cells and the CD34+ population contained only $3.5 \%$ on day 0 .

\section{Mutual distribution of individual populations}

The amounts of cells isolated from $5 \mathrm{ml}$ of BM or PBSCs were quantified. The numbers of $\mathrm{CD} 133+$ cells isolated from the BM of de novo diagnosed CML (CML Ph+) patients were 268,000-873,000 (median 634,000), and the numbers of CD34+ cells isolated from the BM of de novo diagnosed CML patients were 658,000-1,600,000 (median 1,197,000). 
The cell counts for the patients in molecular remission (CML Ph-) were lower: the numbers of CD133+ cells from the BM were 43,000-112,000 (median 76,000) and the numbers of CD34+ cells were 105,000-256,000 (median 183,000).

The cell counts for the healthy volunteers were also different: the numbers of CD133+ cells from the BM were 180,000-320,000 (median 221,000) and the numbers of CD34+ cells were 225,000-550,000 (median 413,000).

The numbers of CD133+ cells isolated from PBSCs were 78,000-288,000 (median 108,000) and the numbers of CD34+ cells isolated from PBSCs were 122,000-608,000 (median 495,000).

For both BM and PBSCs, the cell yields during CD133+ antigen isolation were about 50\% of that during CD34+ antigen isolation.

To validate the presence of two times more CD34+ cells in both bone marrow and PBSC, we performed FACS analysis directly on the harvested samples. Because the distributions of both CD133+ and CD34+ cells are between $0.3 \%$ and $1.2 \%$, the significance of the FACS analysis would not be sufficient. Therefore, we decided to deplete the lymphocyte fraction in order to obtain an enriched population. The measurements of the CD133+ and CD34+ distributions were performed on BM samples of one de novo CML (one sample), one CML in molecular remission, and one healthy donor and two samples of PBSC. The distributions in the enriched population were $25.3 \% \pm 4.8 \%$ for CD34+ and $13.1 \% \pm 3.4 \%$ for CD133+.

By comparing the expression of the CD133 and CD34 antigens using multicolor flow cytometry, we observed that CD133+ cells were clearly not in the subgroup of CD34+ cells [13]. For example, the BM sub-population sorted from healthy volunteers using the CD133 antigen contained only $72 \%$ of CD34 cells. Table 4 shows the changes in the individual markers (CD133 and CD34) immediately after isolation and during cultivation. 
From the discussion above, it is obvious that BM cells and PBSCs differ significantly. The CD133+ and CD34+ PBSC populations demonstrate a relatively large overlap; however, for the $\mathrm{BM}$, the CD133+/34- subpopulation represents more than $30 \%$ of the entire CD133+ population (Table 4).

\section{Analysis of the distribution of lineage-committed progenitors}

Flow cytometry was used to study the distributions of the following antigens: CD71 for erythroid progenitors, CD10 for lymphocytic progenitors and CD33 for myeloid progenitors. For the CD71 antigen, only day 0 was included in the study because EPO was not included in the cultivation medium; therefore, differentiation into the erythroid line was not supported. The average median of these populations was $5.4 \% \pm 1.3 \%$ (data not shown). The distribution was thus sufficient in all populations to permit the successful reconstitution of erythropoiesis in the presence of the relevant cytokines. Significant differences among the populations were not observed during analysis of the myeloid and lymphoid line markers. The p-values for comparisons between the individual populations were between 0.625 and 0.961 . During cultivation, similar increases were observed across all populations (Figure 4).

The CFU-GM and CFU-E formations were used to compare the colony-forming capacities of CD133 and CD34 cells derived from the BM of the same healthy volunteer. In five separate experiments, cells were cultured for 15 days in methylcellulose-based semi-solid medium. CD133 and CD34 cells displayed non-significant differences in CFU-GM formation (median number of colonies 43, cf. 39).

At the beginning of the experiment, all BM populations showed equal distributions of the CD71 marker. However, they showed different numbers of colonies during CFU-E experiments. Even though the differences in the number of colonies generated from CD133 
and CD34 cells were not significant (at $p<0.05$ ), larger numbers of these colonies were found in CD133 cells (median number of colonies was 36, cf. 25)

\section{Analysis of VEGF distribution}

As stated above, the presence of sinusoidal progenitor cells seems to be one of the most important factors for successful transplantation. The VEGFR antigen was used to monitor this subpopulation. As shown in Table 5 and Figure 5, the amount of cells bearing this antigen was significantly $(\mathrm{p}=0.0093)$ higher in the $\mathrm{CD} 133+\mathrm{BM}$ populations compared to the CD34+ BM population. Furthermore, these results indicate that the concentration of these cells is not high enough to negatively affect the reconstitution of hematopoiesis.

\section{Discussion}

Currently, the transplantation of hematopoietic stem cells is one of the most extensively used treatments for multiple types of leukemia.

The transplantation of hematopoietic stem cells depends on four main factors: homing, which is influenced by the presence of adhesive molecules in the graft; graft engraftment, which is an immunological process; reconstitution of the blood cell population; and reconstitution of the stem cell population, which is related to the presence of stem cells in the graft. Unfortunately, although these four factors have been extensively studied, the probability of non-relapse mortality is still far from zero. This problem provides the motivation for further investigation of the suitability of the most frequently used source of hematopoietic stem cells, CD34+ cells from PBSCs. Many studies that aimed to define the total amount of CD34+ cells $[14,15]$ can be found in the literature.

This study focused on the CD133 and CD34 populations from BM and PBSCs. These populations were compared in terms of their mutual distributions. An attempt was made to 
evaluate the distributions of cells for the fast and permanent reconstitution of hematopoiesis and the presence of cells capable of reconstituting sinusoidal endothelial cells.

The first aim of this article was to determine the amount of cells that could be obtained from a given volume of BM or PBSCs and the expansion potential of the individual populations. Because the sample used for isolation was split into two identical portions before MACS separation, it was possible to determine the population distributions in the samples. As described in the Results section, the cell yields for the CD133+ antigen were always about $50 \%$ of those for the CD34+ antigen in both the BM and PBSCs. Thus, this population is minor compared with the CD34+ population. A comparison of the relationships between these two populations resulted in the hypothesis that there is a functional hierarchy between CD133 and CD34 [16]. This hypothesis was also based of the expression profiles for the two populations [17]. A comparison of the expansion potentials was also very interesting. CD133+ cells had a more than two-fold higher expansion potential than the CD34+ cells, even for a short-term 6-day cultivation. Furthermore, it was clear that the CD133+ population also contained a high percentage of CD34- cells that are capable of expressing CD34+ during cultivation. Therefore, those cells can be regarded as a more primitive cell type.

Some authors have suggested that the CD34- cell subpopulation is fully capable of reconstituting hematopoiesis $[18,19]$. It is widely accepted that the more primitive population of HSCs does not express the CD38 antigen [20]. This antigen is expressed even on lineagecommitted progenitors and especially on immune system cells, in which it is responsible for cell-to-cell interactions [21]. In this study, we demonstrated that the CD133 population (especially from the BM) contained a significantly higher amount of CD133+/CD38- cells compared with the CD34+ population. In the CD38- population, quiescent stem cells should also be present. Over long periods of time, those cells remain in the BM in a quiescent, nondividing state and are localized in the stem cell niches. They are also responsible for 
hematopoietic homeostasis and the creation of a stem cell pool hierarchy by asymmetric self- 
contains a higher percentage of EPCs than the CD34+ population. EPCs support the creation of sinusoidal endothelial cells. Endothelial cells are a mandatory component of the BM niche and play an important role in neoangiogenesis [9]. During the evaluation of the VEGFR antigen (EPC marker) on BM cells, significant differences were not observed among the CD34 sub-populations (CML Ph+/Ph-, healthy volunteers). Significant differences were also not observed among CD133 sub-populations (CML Ph+/Ph-, healthy volunteers) [26].

The number of EPCs was measured in the CD34+ and CD133+ populations, and a significant difference was observed. The high pluripotent plasticity of CD133+ VGFR+ and CD34+ VEGFR+ cells was demonstrated using cultivation experiments. These cells did not proliferate into endothelial cells in the presence of relevant growth factors. During cultivation, the VEGFR antigen disappeared. Because an increase in apoptotic cell death corresponding to the percentage of EPCs was not observed during culture (97\% viability), we suggest that the cultivation environment induced proliferation into the hematopoietic pathway.

Many recent studies have reported that the CD133+ cell population is either a subpopulation of CD34 cells [27-30] or an independent population that is fully capable of supporting or reconstituting hematopoiesis for both patients and SCID mice [31].

There are articles in which CD133 was reported to be a marker for a new selection strategy for the purification of autologous grafts and transplantation [32]. In an article by Isidori [33], the capacity of positively selected autologous CD133+ hematopoietic stem cells (HSCs) to reconstitute lymphomyelopoiesis in chronic lymphocytic leukemia is described. The authors state that the reinfusion of highly purified CD133+ HSCs facilitated a rapid and sustained recovery of hematopoiesis after myeloablative treatment in resistant/relapsed CLL patients.

The aim of the study by Hess et al. [34] was to identify an alternative HSC population to the standard CD34+ marker and show that cell selection based on ALDH activity and CD133 
expression provides a novel method for purification of HSCs with long-term repopulating capacity

Even when samples from patients with $\mathrm{CML}(\mathrm{Ph}+, \mathrm{Ph}-)$ were compared with samples from healthy volunteers, significant differences were observed in both cellular proliferation and the expression of relevant $\mathrm{CD}$ antigens in the individual populations.

In the PBSC populations, significant differences between CD133 and CD34 were not observed. The statistical significance $(\mathrm{p})$ values of the monitored parameters were near 0.06 . In contrast, the differences for the BM were significant at $\mathrm{p}=0.015$.

This work demonstrates that the CD133+ cell population of BM shows many differences compared with the other populations included in the study. During the experiments described above, the $\mathrm{CD} 133+\mathrm{BM}$ population had better cultivation and expansion potentials than the CD34+ population.

The population also contained a higher percentage of non-dividing CD38- cells. Those cells can be assumed to be more primitive component of the bone marrow, which may be important for long term hematopoiesis reconstitution. During analysis of the CFU-GM and CFU-E experiments, we did not observe significant differences between the CD133+ and CD34+ cells; therefore, from the perspective of short-term hematopoiesis, both populations are comparable.

Furthermore our study confirmed that the CD133+ BM population contains a significantly higher percentage of the so called endothelial progenitors in the CD133 population. Those cells play a crucial role in the reconstitution of the BM architecture and thus in engraftment. In summary, the CD133+ selected population has many advantages over other studied populations. 
There are many studies available in which the CD133+ enriched population was used for

\section{Acknowledgments}

This work was generously supported by the Ministry of Education of the Czech Republic grant MSM-0021622430, NPVII (2B06052). We would like to thank the Dept. of Internal Medicine - Hematooncology, Hospital Brno, Jihlavska 20, 62500 Brno, Czech Republic, especially Zdenek Koristek M.D. and Zdenek Racil M.D. for the collection of blood and bone marrow samples. 


\section{References}

1. Gratwohl A, Baldomero H, Horisberger B, Schmid C, Passweg J and Urbano-Ispizua A. (2002). Current trends in hematopoietic stem cell transplantation in Europe. Blood 2002; 100: 2374-2386.

2. Civin CI and Loken MR. (1987). Cell surface antigens on human marrow cells: dissection of hematopoietic development using monoclonal antibodies and multiparameter flow cytometry. Int J Cell Cloning 1987; 5: 267-288.

3. Tavassoli M. (1981). Structure and function of sinusoidal endothelium of bone marrow. Prog Clin Biol Res 1981; 59B: 249-256.

4. Summers YJ, Heyworth CM, de Wynter EA, Hart CA, Chang J and Testa NG. (2004). AC133+ G0 cells from cord blood show a high incidence of long-term cultureinitiating cells and a capacity for more than 100 million-fold amplification of colonyforming cells in vitro. Stem Cells 2004; 22(5): 704-15.

5. Kuçi S, Kuçi Z, Schmid S et al. (2008). Efficient in vitro generation of adult multipotent cells from mobilized peripheral blood CD133+ cells. Cell Prolif 2008; 41(1): 12-27.

6. Goussetis E, Theodosaki M, Paterakis G, et al. (2003). Kinetics of quiescent cord blood stem/progenitor cells with high proliferative potential in stem-cell expansion culture. Cytotherapy 2003; 5(6): 500-8.

7. Hooper AT, Butler JM, Nolan DJ, et al. (2009). Engraftment and reconstitution of hematopoiesis is dependent on VEGFR2-mediated regeneration of sinusoidal endothelial cells. Cell Stem Cell 2009; 4(3): 263-74.

8. Hristov M and Weber C. (2008). Endothelial progenitor cells in vascular repair and remodeling. Pharmacol Res 2008; 58(2):1 48-51; e-pub ahead of print 5 August 2008; doi:10.1016/j.phrs.2008.07.008 
9. Peichev M, Naiyer AJ, Pereira D, et al. (2000). Expression of VEGFR-2 and AC133 by circulating human CD34(+) cells identifies a population of functional endothelial precursors. Blood 2000; 95(3): 952-8.

10. Baccarani M, Cortes J, Pane F, et al. (2009). Chronic myeloid leukemia: an update of concepts and management recommendations of European LeukemiaNet. J Clin Oncol. 2009 Dec 10;27(35):6041-51.

11. Racil Z, Razga F, Buresova L, et al. (2010)The assessment of human organic cation transporter 1 (hOCT1) mRNA expression in patients with chronic myelogenous leukemia is affected by the proportion of different cells types in the analyzed cell population. Am J Hematol. $2010 \mathrm{Jul} ; 85(7): 525-8$.

12. Holyoake T, Jiang X, Eaves C, Eaves A. (1999). Isolation of a highly quiescent subpopulation of primitive leukemic cells in chronic myeloid leukemia. Blood 1999; 94(6): 2056-64.

13. Peterkova M, Koutna I, Simara P, Stejskal S, Tesarova L. (2009). The in vitro proliferation potential of $\mathrm{CD} 133+$ versus CD34+ hematopoietic stem cells. Experimental Hematology 2009;37 (Suppl 1): 35-36.

14. Yoon DH, Sohn BS, Jang G, Kim EK, et al. (2009). Higher infused CD34+ hematopoietic stem cell dose correlates with earlier lymphocyte recovery and better clinical outcome after autologous stem cell transplantation in non-Hodgkin's lymphoma. Transfusion 2009; e-pub ahead of print 5 August 2008; 11 May 2009; doi: 10.1111/j.1537-2995.2009.02202.x

15. Siena S, Schiavo R, Pedrazzoli P and Carlo-Stella C. (2000). Therapeutic relevance of CD34 cell dose in blood cell transplantation for cancer therapy. J Clin Oncol 2000; 18(6): 1360-77. 
16. Goussetis E, Theodosaki M, Paterakis G, et al. (2000). A functional hierarchy among the CD34+ hematopoietic cells based on in vitro proliferative and differentiative potential of AC133+CD34(bright) and AC133(dim/)-CD34+ human cord blood cells. J Hematother Stem Cell Res 2000; 9(6): 827-40.

17. He X, Gonzalez V, Tsang A, Thompson J, Tang TC and Harris DT. (2005). Differential gene expression profiling of CD34+ CD133+ umbilical cord blood hematopoietic stem progenitor cells. Stem Cells Dev 2005; 14(2): 188-98.

18. Zanjani ED, Almedia-Porada G, Livingstone AG, Zeng H and Ogawa M. (2003). Reversible expression of CD34 by adult human bone marrow long-term engrafting hematopoietic stem cells. Exp Hematol 2003; 31: 406-412.

19. Verfaillie CM, Almedia-Porada G, Wissink S and Zanjani ED. (2000). Kinetics of engraftment of CD34- and CD34+ cells from mobilized blood differs from that of CD34- and CD34+ cells from bone marrow. Exp Hematol 2000; 28: 1071-1079.

20. McKenzie JL, Gan OI, Doedens M and Dick JE. (2007). Reversible cell surface expression of CD38 on CD34- positive human hematopoietic repopulating cells. Exp Hematol 2007; 35(9): 1429-36.

21. Deaglio S, Mehta K and Malavasi F. (2001). Human CD38: a (r)evolutionary story of enzymes and receptors. Leuk Res 2001; 25(1): 1-12.

22. Yahata T, Muguruma Y, Yumino S, Sheng Y, et al. (2008). Quiescent human hematopoietic stem cells in the bone marrow niches organize the hierarchical structure of hematopoiesis. Stem Cells 2008; 26(12): 3228-36; e-pub ahead of print 12 December 2008; doi:10.1634/stemcells.2008-0552

23. Loges S, Fehse B, Brockmann MA, et al. (2004). Identification of the adult human hemangioblast. Stem Cells Dev 2004; 13(3): 229-42. 
24. Quirici N, Soligo D, Caneva L, Servida F, Bossolasco P, Deliliers GL. (2001). Differentiation and expansion of endothelial cells from human bone marrow CD133(+) cells. Br J Haematol 2001; 115(1): 186-94.

25. Li XM, Hu Z, Jorgenson ML, Wingard JR, Slayton WB. (2008). Bone marrow sinusoidal endothelial cells undergo nonapoptotic cell death and are replaced by proliferating sinusoidal cells in situ to maintain the vascular niche following lethal irradiation. Exp Hematom 2008; 36(9): 1143-1156.

26. Krauth MT, Simonitsch I, Aichberger KJ, et al. (2004). Immunohistochemical detection of VEGF in the bone marrow of patients with chronic myeloid leukemia and correlation with the phase of disease. Am J Clin Pathol 2004; 121(4):473-81.

27. Matsumoto K, Yasui K, Yamashita N, et al. (2000). In vitro proliferation potential of AC133 positive cells in peripheral blood. Stem Cells 2000; 18(3): 196-203.

28. Lang P, Bader P, Schumm M, et al. (2004). Transplantation of a combination of CD133+ and CD34+ selected progenitor cells from alternative donors. Br J Haematol 2004; 124(1): 72-9.

29. Freund D, Oswald J, Feldmann S, Ehninger G, Corbeil D, Bornhäuser M. (2006). Comparative analysis of proliferative potential and clonogenicity of MACSimmunomagnetic isolated CD34+ and CD133+ blood stem cells derived from a single donor. Cell Prolif 2006; 39(4): 325-32.

30. Hemmoranta H, Hautaniemi S, Niemi J, et al. (2006). Transcriptional profiling reflects shared and unique characters for CD34+ and CD133+ cells. Stem Cells Dev 2006; 5(6): 839-51.

31. Gordon PR, Leimig T, Babarin-Dorner A, et al. (2003). Large-scale isolation of CD133+ progenitor cells from G-CSF mobilized peripheral blood stem cells. Bone Marrow Transplant 2003; 1(1): 17-22. 
32. Koehl U, Zimmermann S, Esser R, et al. (2002). Autologous transplantation of CD133 selected hematopoietic progenitor cells in a pediatric patient with relapsed leukemia. Bone Marrow Transplant 2002; 29, 927-930.

33. Isidori A, Motta MR, Tani M, et al. (2007). Positive selection and transplantation of autologous highly purified CD133(+) stem cells in resistant/relapsed chronic lymphocytic leukemia patients results in rapid hematopoietic reconstitution without an adequate leukemic cell purging. Biol Blood Marrow Transplant. 2007 Oct;13(10):1224-32.

34. Hess DA, Wirthlin L, Craft TP, et al. (2006). Selection based on CD133 and high aldehyde dehydrogenase activity isolates long-term reconstituting human hematopoietic stem cells. Blood. 2006 Mar 1;107(5):2162-9. 
Figure legends:

Figure 1. The flow cytometric analysis of experiments with CFSE. A) CD34+ cells from BM of healthy volunteers after three-day cultivation with CFSE. B) CD133+ cells from BM of healthy volunteers after three-day cultivation with CFSE C) CD34+ cells from BM of healthy volunteers after six-day cultivation with CFSE. D) CD133+ cells from BM of healthy volunteers after six-day cultivation with CFSE. The demecolcine control is highlighted only in subfigure A for better orientation in figures. CD133+ and CD34+ cells were stained with a PE-conjugated antibody, and CFSE intensities were measured by the FITC channel as described in the materials and methods section.

Figure 2. The distribution of analysed populations in individual divisions after five days of cultivation.

Figure 3. The flow cytometric analysis of CD133+/CD38- and CD34+/CD38- populations from bone marrow obtained from healthy volunteers. CD133+ and CD34+ cells were stained with PE-conjugated antibody and CD38+ with APC-conjugated antibody as described in the materials and methods section.

Figure 4. The visualization of CD33+ and CD10+ cells in the analyzed populations on day 0 and after 3 and 6 days of cultivation. The numbers for BM populations from healthy volunteers are represented by their median value.

Figure 5. The graphic visualization of VEGFR+ cells from healthy volunteers' BM in all analyzed populations on day 0 and after 3 and 6 days of cultivation. 
Tables

Table 1. The amount of input cells in the culture and fold increase of cell amount after three and six days of cultivation. The measured population viability in Day 0 was $99 \%$ in all cases.

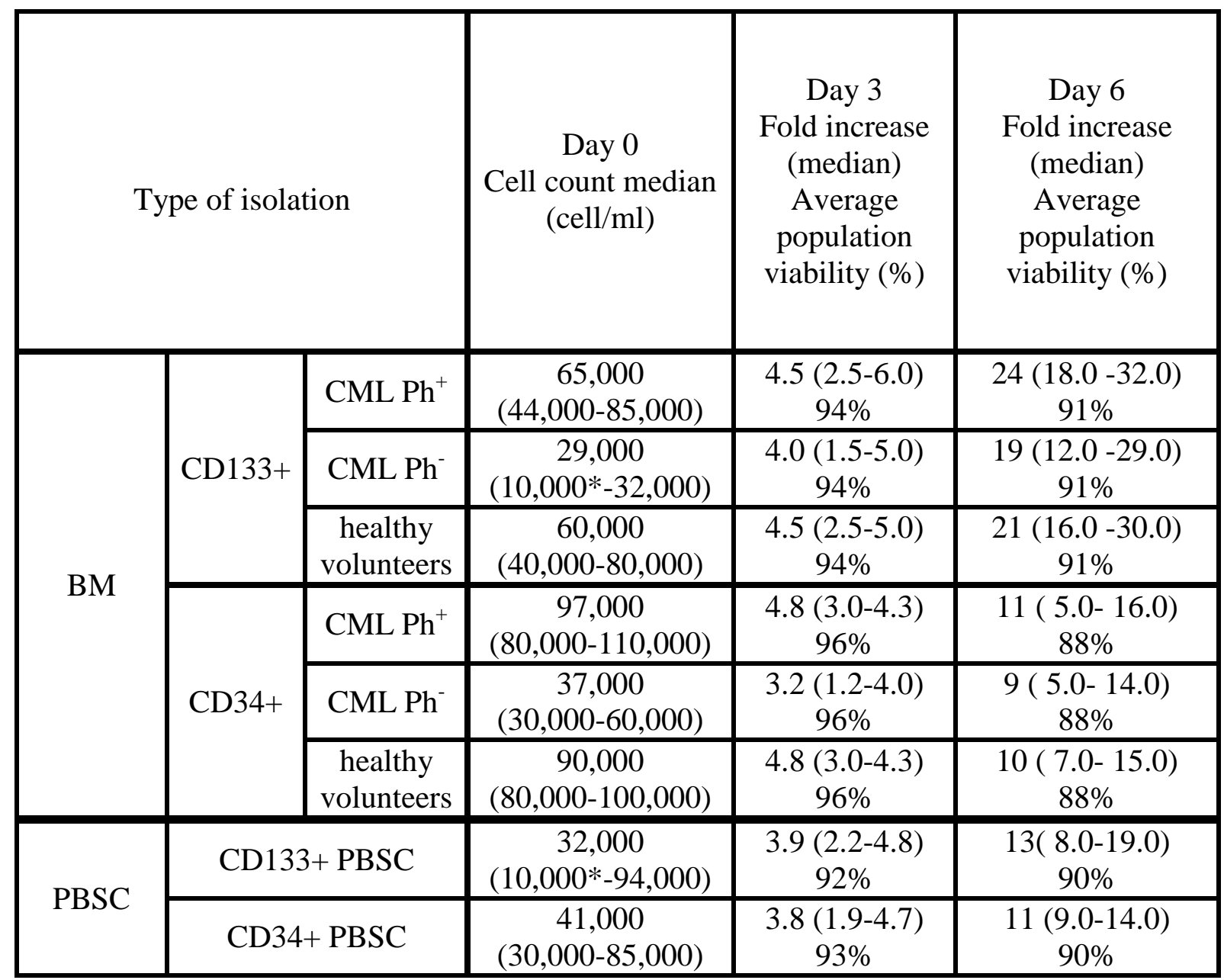

*The amount of cells bellow 30,000 was not included in the calculation of fold increase. 
Table 2. The percentage of cells (median) in individual divisions after a six-day cultivation *healthy volunteers - H.V.

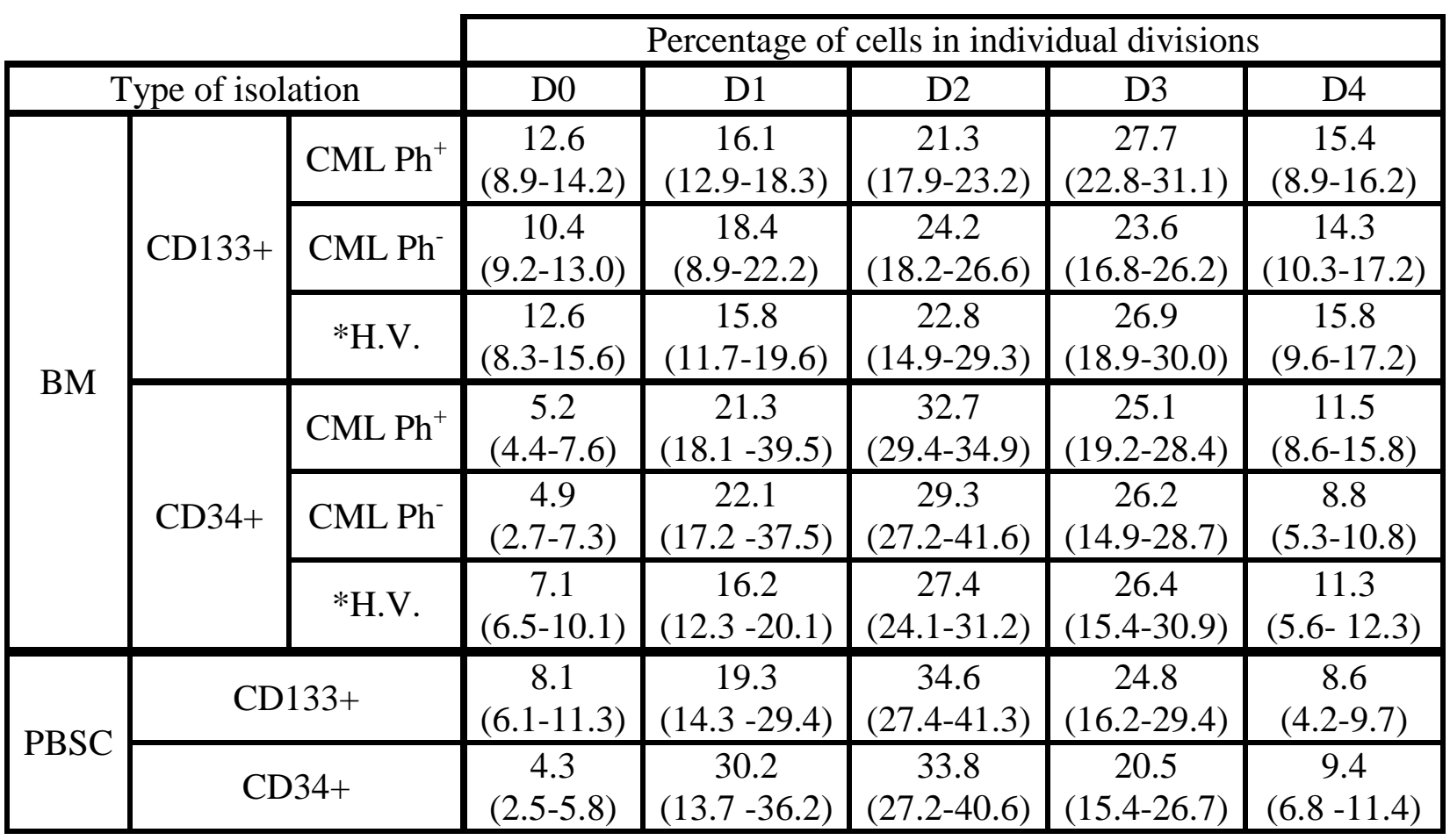


Table 3. The percentage of CD38 in analyzed populations on day 0 and after 3 and 6 days of cultivation.

* "H.V." stands for healthy volunteers

\begin{tabular}{|c|c|c|c|c|c|c|c|c|}
\hline \multirow{3}{*}{$\begin{array}{l}\text { Content of } \\
\mathrm{CD} 38^{-} \text {in } \\
\text { individual } \\
\text { populations }\end{array}$} & \multicolumn{6}{|c|}{$\mathrm{BM}($ median $\%)$} & \multicolumn{2}{|c|}{ PBSC (median \%) } \\
\hline & \multicolumn{3}{|c|}{$\mathrm{CD} 133+/ \mathrm{CD}^{2} 8^{-}$} & \multicolumn{3}{|c|}{ CD34+/CD38- } & \multirow[b]{2}{*}{ 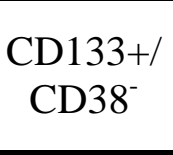 } & \multirow{2}{*}{$\begin{array}{c}\mathrm{CD} 34+/ \mathrm{CD} 3 \\
8^{-}\end{array}$} \\
\hline & $\begin{array}{l}\mathrm{CML} \\
\mathrm{Ph}^{+}\end{array}$ & $\begin{array}{l}\mathrm{CML} \\
\mathrm{Ph}^{-}\end{array}$ & H.V.* & $\begin{array}{l}\mathrm{CML} \\
\mathrm{Ph}^{+}\end{array}$ & $\begin{array}{l}\mathrm{CML} \\
\mathrm{Ph}^{-}\end{array}$ & H.V.* & & \\
\hline Day 0 & 8.4 & 6.6 & 9.2 & 3.1 & 2.9 & 3.5 & 5.4 & 1.2 \\
\hline 3 & 5.1 & 3.8 & 4.2 & 2.1 & 1.5 & 2.5 & 1.6 & 1.2 \\
\hline 6 & 2.6 & 2.3 & 2.4 & 1.6 & 1.4 & 1.2 & 0.7 & 0.6 \\
\hline
\end{tabular}


Table 4. The percentage of mutual distribution of CD133+ and CD34+ antigens of analyzed populations on day 0 and after 3 and 6 days of cultivation. For example cells isolated using CD133 antigen from BM of CML Ph+ patients contained only 52\% of CD34+ cells in day 0. * "H.V." stands for healthy volunteers

\begin{tabular}{|c|c|c|c|c|c|c|c|c|}
\hline & \multicolumn{6}{|c|}{$\mathrm{BM}$} & \multicolumn{2}{|c|}{ PBSC } \\
\hline & \multicolumn{3}{|c|}{$\begin{array}{l}\text { CD133+ isolation } \\
\text { (median) }\end{array}$} & \multicolumn{3}{|c|}{$\begin{array}{l}\text { CD34+ isolation } \\
\text { (median) }\end{array}$} & \multirow{2}{*}{$\begin{array}{l}\text { CD133+ } \\
\text { isolation } \\
\text { (median) }\end{array}$} & \multirow{2}{*}{$\begin{array}{l}\text { CD34+ } \\
\text { isolation } \\
\text { (median) }\end{array}$} \\
\hline CD34+ antigen & $\begin{array}{c}\mathrm{CML} \\
\mathrm{Ph}^{+}\end{array}$ & $\begin{array}{c}\mathrm{CML} \\
\mathrm{Ph}^{-}\end{array}$ & H.V.* & $\begin{array}{c}\mathrm{CML} \\
\mathrm{Ph}^{+}\end{array}$ & $\begin{array}{c}\mathrm{CML} \\
\mathrm{Ph}^{-}\end{array}$ & H.V.* & & \\
\hline Day 0 & $52 \%$ & $64 \%$ & $72 \%$ & $98 \%$ & $95 \%$ & $98 \%$ & $74 \%$ & $97 \%$ \\
\hline 3 & $56 \%$ & $59 \%$ & $61 \%$ & $74 \%$ & $69 \%$ & $59 \%$ & $62 \%$ & $68 \%$ \\
\hline 6 & $51 \%$ & $54 \%$ & $47 \%$ & $42 \%$ & $52 \%$ & $45 \%$ & $56 \%$ & $42 \%$ \\
\hline \multicolumn{9}{|l|}{$\begin{array}{l}\text { CD133+ } \\
\text { Antigen }\end{array}$} \\
\hline Day 0 & $94 \%$ & $97 \%$ & $96 \%$ & $45 \%$ & $51 \%$ & $53 \%$ & $97 \%$ & $62 \%$ \\
\hline 3 & $65 \%$ & $62 \%$ & $67 \%$ & $28 \%$ & $29 \%$ & $34 \%$ & $67 \%$ & $46 \%$ \\
\hline 6 & $42 \%$ & $48 \%$ & $29 \%$ & $19 \%$ & $19 \%$ & $18 \%$ & $39 \%$ & $29 \%$ \\
\hline
\end{tabular}


Table 5. The percentage of VEGFR-positive cells in all analyzed populations on day 0 and after 3 and 6 days of cultivation.

* "H.V." stands for healthy volunteers

\begin{tabular}{|c|c|c|c|c|c|c|c|c|}
\hline \multirow{2}{*}{$\begin{array}{c}\text { VEGF+ } \\
\text { antigen }\end{array}$} & \multicolumn{5}{|c|}{ BM (median \%) } & \multicolumn{2}{c|}{ PBSC (median \%) } \\
\cline { 2 - 9 } & $\begin{array}{c}\text { CML } \\
\mathrm{Ph}^{+}\end{array}$ & $\begin{array}{c}\text { CML } \\
\mathrm{Ph}^{-}\end{array}$ & H.V.* & $\begin{array}{c}\text { CML } \\
\mathrm{Ph}^{+}\end{array}$ & $\begin{array}{c}\text { CML } \\
\mathrm{Ph}^{-}\end{array}$ & H.V.* & & \\
\hline Day 0 & 17.1 & 13.8 & 12.1 & 6.6 & 5.2 & 7.4 & 11.8 & 10.6 \\
\hline 3 & 2.4 & 2.1 & 1.9 & 1.3 & 1.6 & 2.3 & 1.2 & 1.5 \\
\hline 6 & 0.5 & 0.7 & 0.3 & 0.8 & 0.9 & 0.7 & 0.5 & 0.5 \\
\hline
\end{tabular}


Click here to download high resolution image

\section{A}
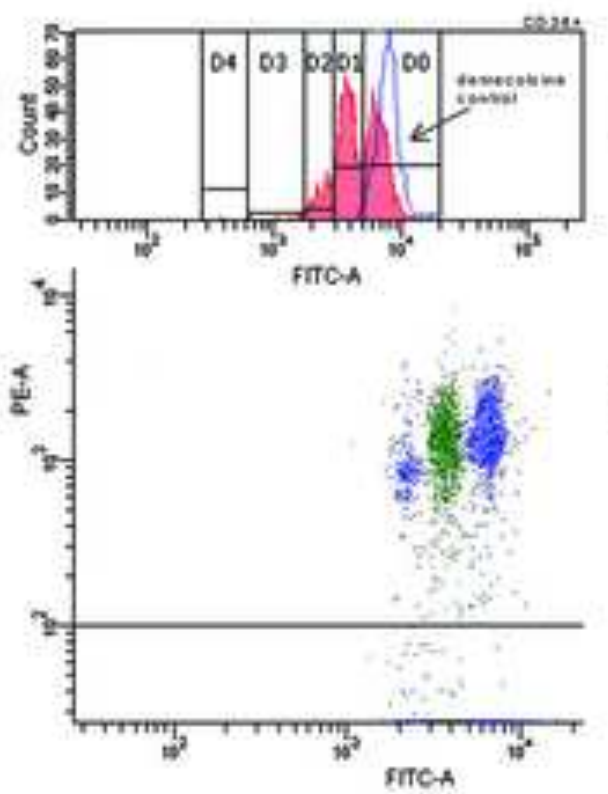

B
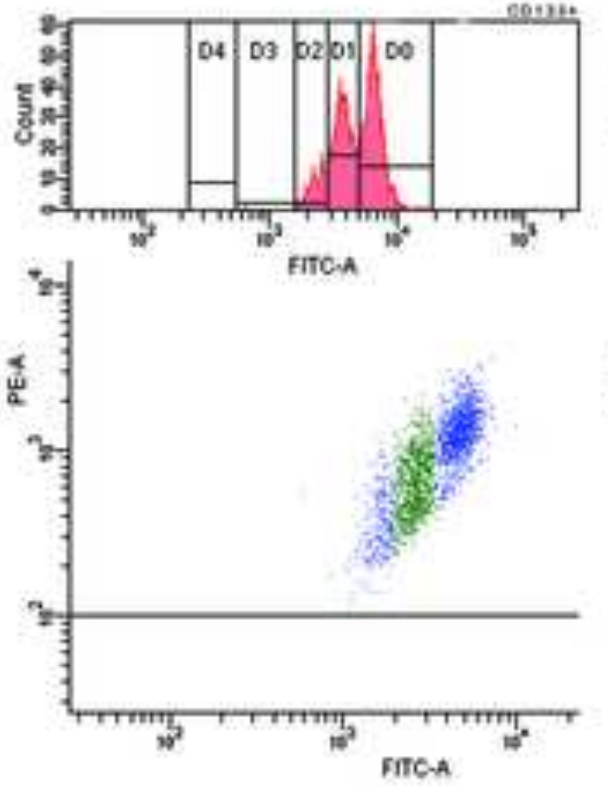

C
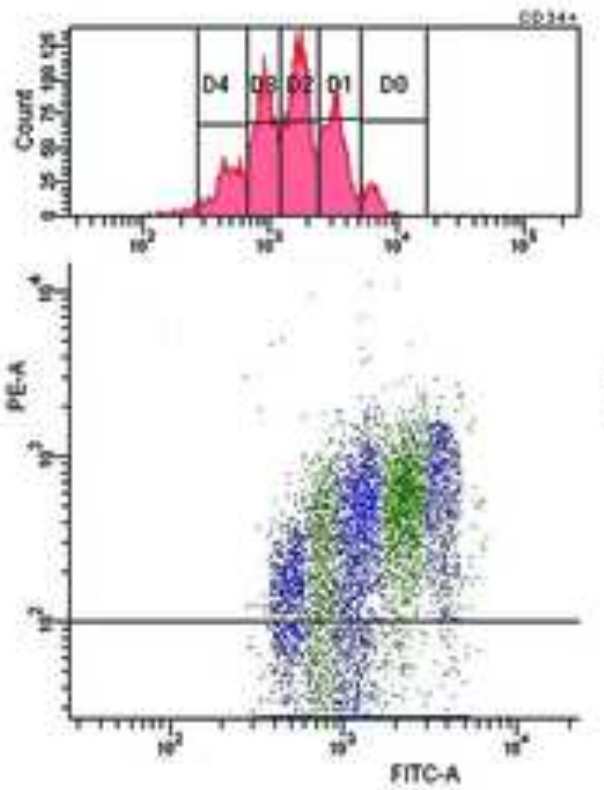

D
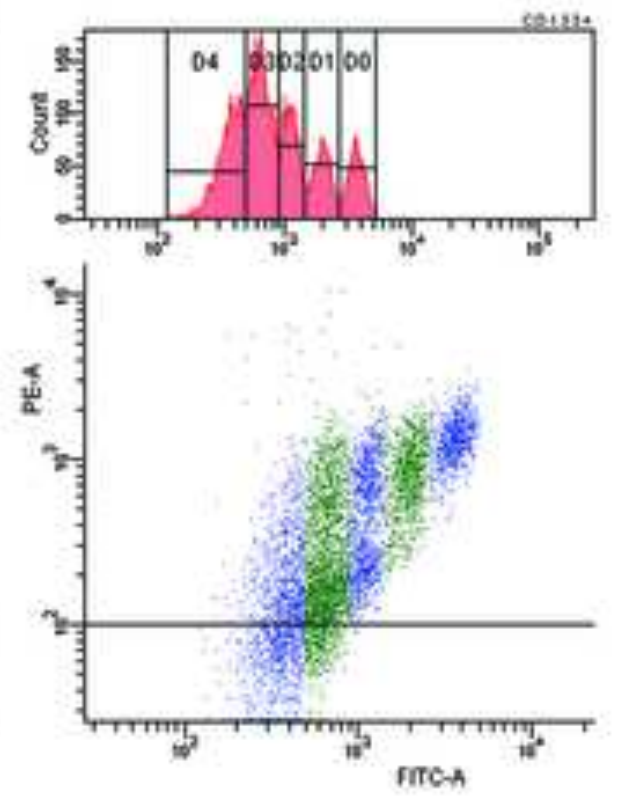
Click here to download high resolution image

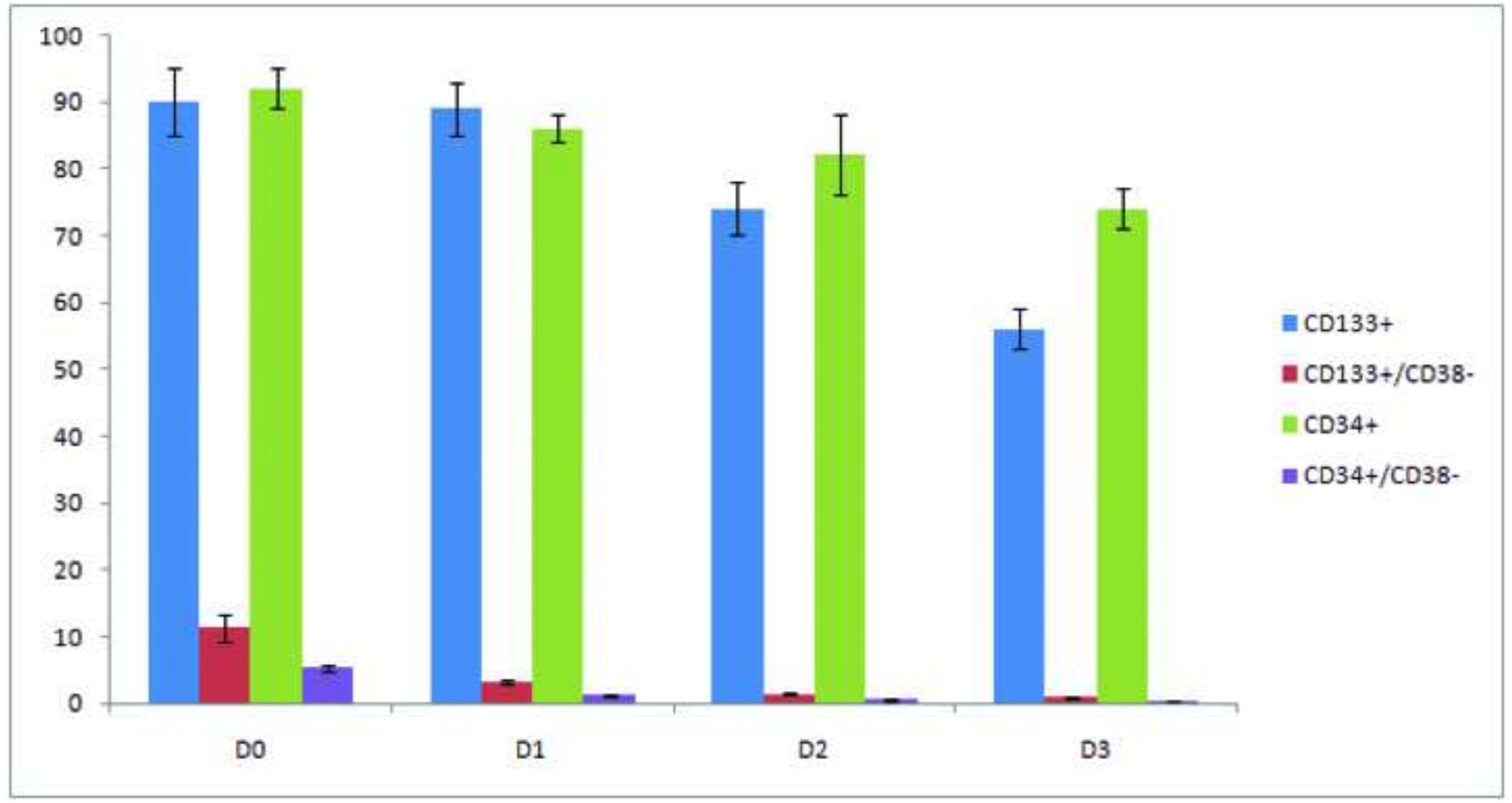


A

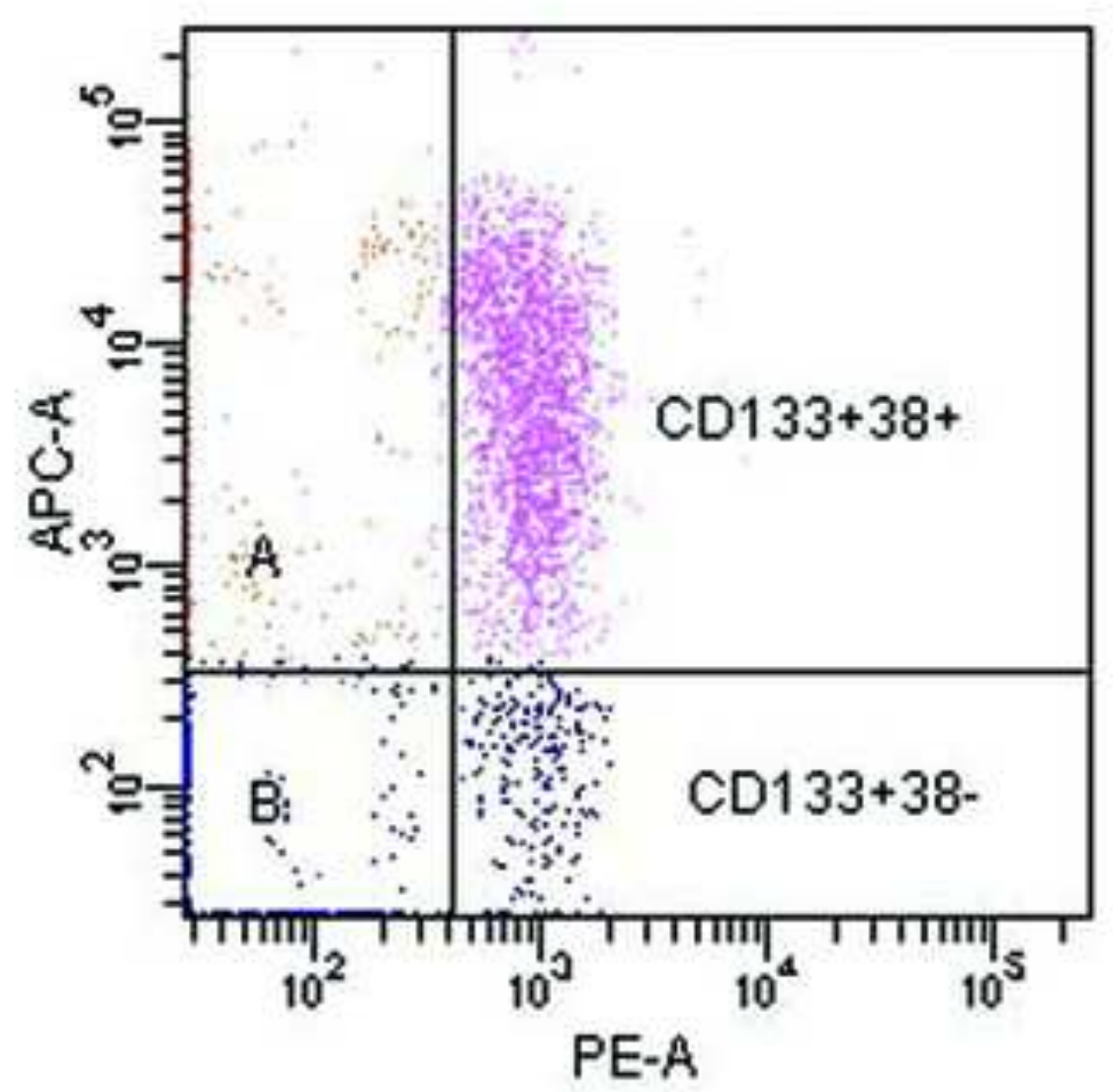

B

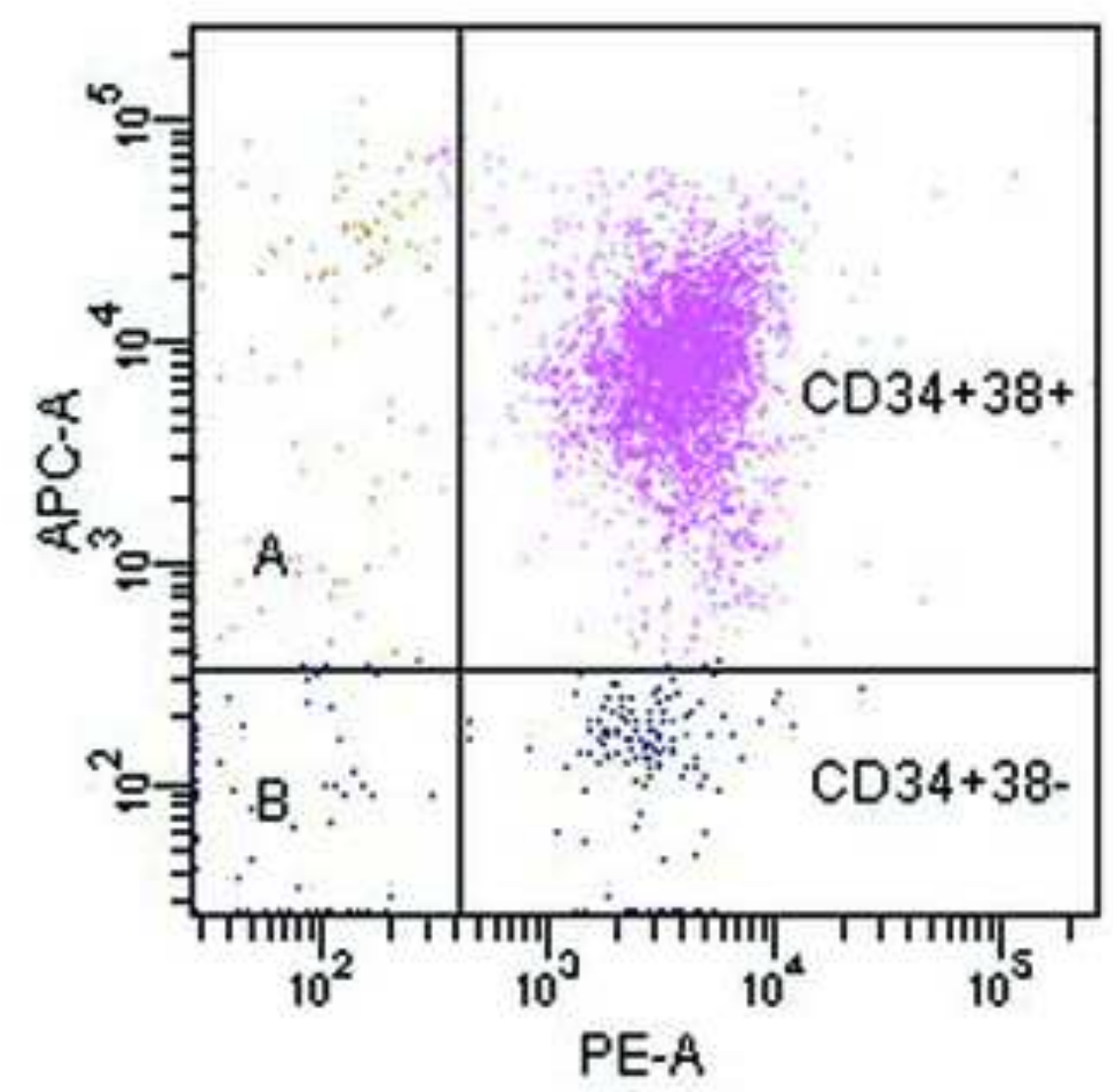


CD33+

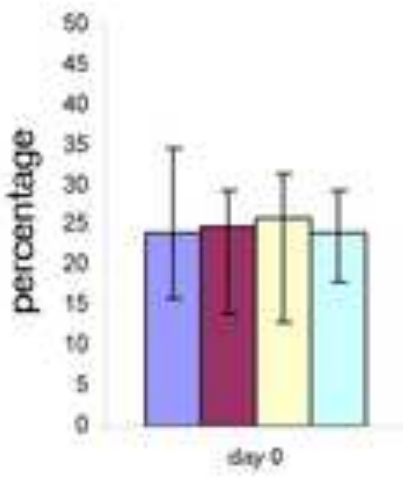

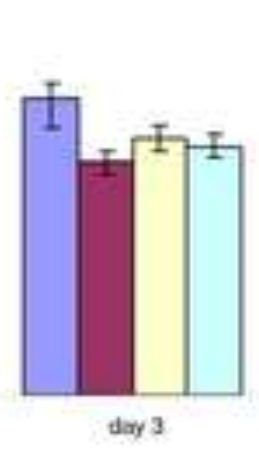

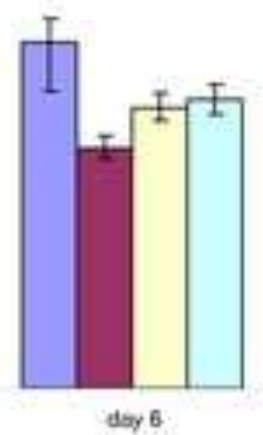

\section{CD10+}

16

14

12

acons3+ (e) 10

aco34 $+(\mathrm{BN})$

口CO133+ (PBSC) cocosen (jesc)

dax 0

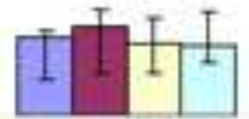

dory 3

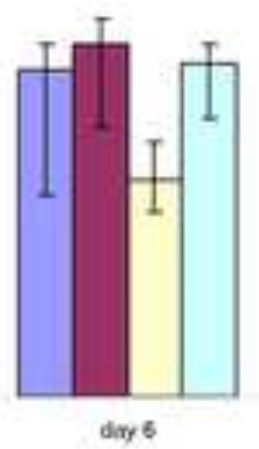

口 acosat (BM $\square C D 133+$ (FESC) acoss + (Pasc) 


\section{VEGF}
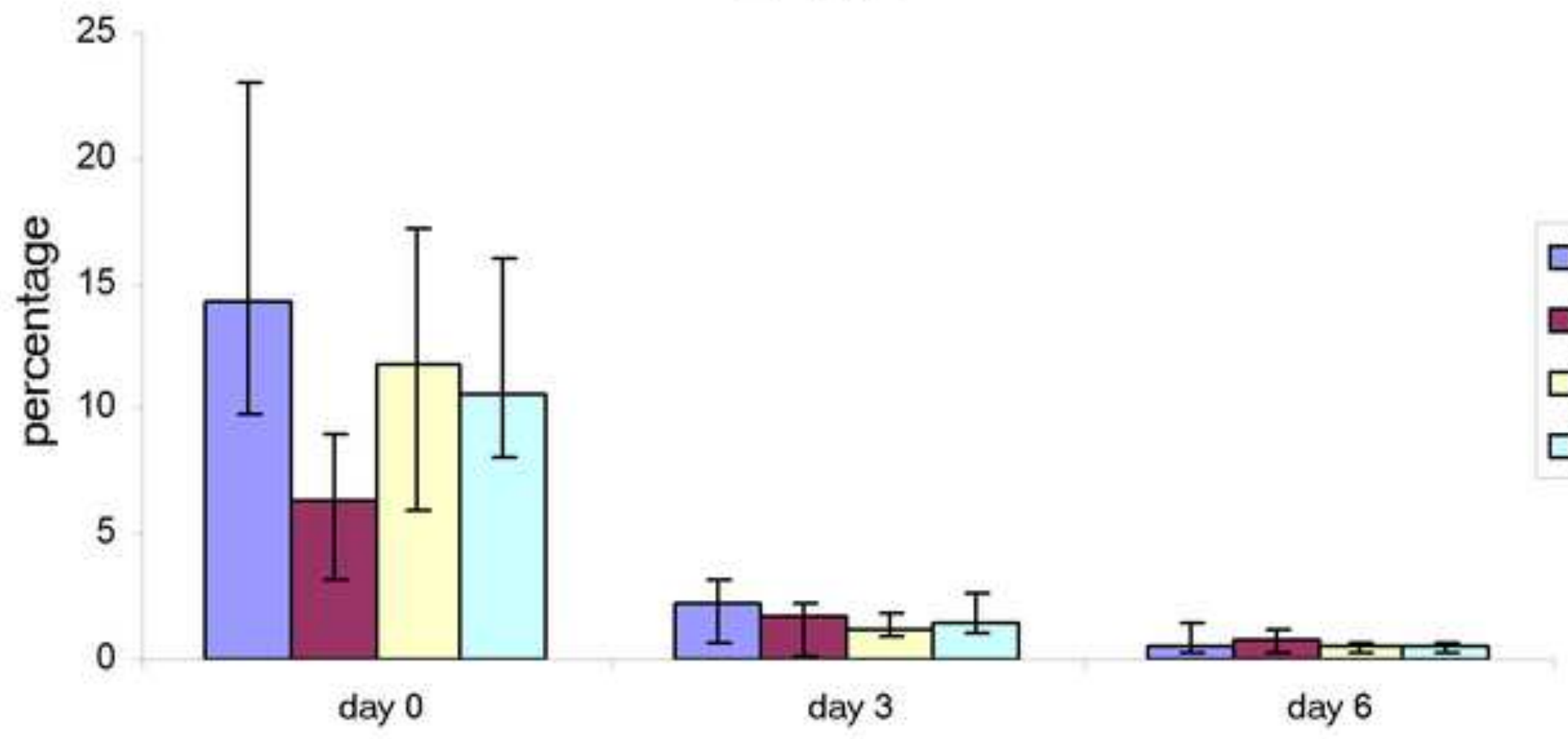

$\square \mathrm{CD} 133+(\mathrm{BM})$

$\square \mathrm{CD} 34+(\mathrm{BM})$

$\square \mathrm{CD} 133+$ (PBSC)

$\square \mathrm{CD} 34+$ (PBSC) 